\title{
Cerebral gene expression and neurobehavioural development after perinatal exposure to an environmentally relevant polybrominated diphenylether (BDE47)
}

\author{
Marte Haave • Kristin Ingvaldsen Folven • Thomas Carroll • Chris Glover • \\ Einar Heegaard • Trond Brattelid • Christer Hogstrand • Anne-Katrine Lundebye
}

Received: 14 December 2010 / Accepted: 12 May 2011 / Published online: 2 June 2011

(C) The Author(s) 2011. This article is published with open access at Springerlink.com

\begin{abstract}
Nutrients in seafood are known to be beneficial for brain development. Effects of maternal exposure to $2,2^{\prime}, 4,4^{\prime}$ tetrabromo diphenylether (BDE47) was investigated, alongside the potential ameliorating impact of seafood nutrients, through assessment of neurobehaviour and gene expression in brain and liver. Developing mice were exposed during gestation and lactation via dams dosed through casein- or salmon-based feed, spiked with BDE47. Two concentrations were used: a low level $(6 \mu \mathrm{g} / \mathrm{kg}$ feed) representing an environmentally realistic concentration and a high level $(1,900 \mu \mathrm{g} / \mathrm{kg}$ feed $)$ representing a BDE47 intake much higher than expected from frequents consumption of contaminated seafood. Experimental groups were similar with respect to reproductive success, growth and physical
\end{abstract}

Electronic supplementary material The online version of this article (doi:10.1007/s10565-011-9192-8) contains

supplementary material, which is available to authorized users.

M. Haave $(\bowtie) \cdot$ K. I. Folven • C. Glover • T. Brattelid •

C. Hogstrand $\cdot$ A.-K. Lundebye

National Institute of Nutrition

and Seafood Research (NIFES),

PO Box 2029, Nordnes,

5817 Bergen, Norway

e-mail: mha@nifes.no

M. Haave $\cdot$ A.-K. Lundebye

Department of Biology, University of Bergen,

PO box 7803, 5020 Bergen, Norway development. Minor, transient changes in neurobehavioural metrics were observed in groups given the highest dose of BDE47. No significant differences in behaviour or development were seen on postnatal day 18 among maternally exposed offspring. Cerebral gene expression investigated by microarray analyses and validated by RT-qPCR showed low fold changes for all genes, despite dose-dependent accumulation of BDE47 in brain tissue. The gene for glutamate ammonia ligase was upregulated compared to control in the casein-based high BDE47diet, suggesting potential impacts on downstream synaptic transmission. The study supported a previously observed regulation of $I g f b p 2$ in brain with BDE47 exposure. Genes for hepatic metabolic enzymes were not influenced by BDE47. Potential neurotoxic effects

T. Carroll $\cdot$ C. Hogstrand

Nutritional Sciences Division, King's College London,

Franklin-Wilkins Building, 150 Stamford Street,

London SE1 9NH, UK

E. Heegaard

Norwegian Forest and Landscape Institute,

Fanaflaten 4, 5244 Fana, Norway

Present Address:

C. Glover

University of Canterbury,

Christchurch, New Zealand 
and neurobehavioural aberrations after perinatal exposure to high levels of BDE47 were not readily observed in mice pups with the present experimental exposure regimes and methods of analysis.

Keywords BDE47 · Brain - Gene expression · Neurobehaviour · Nutrition · Polybrominated diphenylethers

$\begin{array}{ll}\text { Abbreviations } \\ \text { AOAC } & \text { Association of official analytical chemists } \\ \text { BGS } & \text { Brain growth spurt } \\ \text { CNS } & \text { Central nervous system } \\ \text { EFSA } & \text { European Food Safety Authority } \\ \text { FAO } & \text { Food and Agriculture Organization } \\ \text { FDR } & \text { False discovery rate } \\ \text { GC/MS } & \text { Gas chromatography/mass spectrometry } \\ \text { GD } & \text { Gestation day } \\ \text { GLM } & \text { Generalised linear model } \\ \text { GLS } & \text { Generalised least square regression } \\ \text { HPLC } & \text { High performance liquid chromatography } \\ \text { HSI } & \text { Hepatosomatic index } \\ \text { ICP/MS } & \text { Inductively coupled plasma/mass } \\ & \text { spectrometry } \\ \text { IPA } & \text { Ingenuity pathway analyses } \\ \text { IUPAC } & \text { International Union of Pure and } \\ & \text { Applied Chemistry } \\ \text { LME } & \text { Linear mixed effect model } \\ \text { LOQ } & \text { Limit of quantification } \\ \text { NOAEL } & \text { No observable adverse effect level } \\ \text { PND } & \text { Postnatal day } \\ \text { RT-qPCR } & \text { Reverse transcription-quantitative } \\ & \text { polymerase chain reaction } \\ \text { WHO } & \text { World Health Organization } \\ \text { WW } & \text { Wet weight } \\ & \end{array}$

\section{Introduction}

The presence of polybrominated diphenylethers (PBDEs) has been documented in exponentially increasing levels in animals and humans from the 1970s until the present (Meironyte et al. 1999; Noren and Meironyte 2000). Infants are exposed to relatively high levels of PBDEs and other persistent, fat-soluble organohalogens during gestation and lactation (Guvenius et al. 2003; Furst 2006). Several studies have documented neurotoxic effects of PBDEs in vitro (Kodavanti 2005;
Reistad et al. 2006; He et al. 2008), and long-term adverse effects of PBDEs have been shown at doses too low to produce overt toxicity or altered physical development in vivo (Viberg et al. 2006; Gee and Moser 2008). In particular, altered spontaneous behaviour has been seen in mice after exposure to a single low oral dose of PBDEs $[\leq 1 \mathrm{mg} / \mathrm{kg}$ bodyweight (BW)] during the vulnerable brain growth spurt (BGS) (Eriksson et al. 2002; Viberg et al. 2003b, 2006; Gee and Moser 2008). Mechanistic studies have shown changes in the density of cholinergic receptors in the hippocampus and reduced dopamine levels in vivo after PBDE exposure during the BGS (Viberg et al. 2003a; Gee et al. 2008), and intracellular signalling in neurons also seems to be disrupted in vitro (Kodavanti and Derr-Yellin 2002; Kodavanti 2005). These cellular and biochemical changes may underlie the behavioural effects observed. This indicates that changes may be present in both the structure and functionality of the brain after acute exposure to PBDEs.

Seafood is a rich source of many beneficial nutrients as well as a major source of dietary contaminants for seafood consumers (Bonham et al. 2009). International public guidelines advise pregnant women to increase their intake of seafood and oily fish due to the beneficial nutrients (WHO/FAO, 2002; EFSA, 2005), as there is ample evidence of detrimental effects linked to maternal nutritional deficits during gestation (review by Bourre 2006). Moreover, foods and nutrients have been shown to protect against a range of toxic effects. Examples include sequestration of methyl mercury by selenium (Peraza et al. 1998), reduction of the accumulation of pentaand hexachlorobenzene with fish-oil consumption (Umegaki et al. 1995; Umegaki and Ikegami 1998) and reduction of the acute toxicity of dioxins by antioxidants such as vitamins A and E (Alsharif and Hassoun 2004). Epigenetic modifications in offspring by maternal nutrient supplementation have also been shown (Dolinoy et al. 2007). The potential ameliorating effect of dietary nutrients on the toxic response to environmental contaminants needs to be further evaluated. Few experimental studies examine the detrimental effects of exposure to PBDE concentrations and routes of exposure relevant to humans, which would be of interest for dietary advice to consumers.

Structural and functional changes in the brain have been seen after perinatal PBDE exposure 
during the BGS (Viberg et al. 2003a, 2008). It would be expected that such changes were preceded by regulatory changes in, i.e. cerebral gene expression. Toxicogenomics offers the advantage of screening the entire transcriptome and may provide a mechanistic link between early gene expression changes and later functional and structural changes. A toxicogenomic approach may thus accelerate our understanding of the mechanism underlying PBDE toxicity. Despite the demonstrable effects of PBDEs on the central nervous system, there is, to our knowledge, only one previous in vivo study concerning toxicogenomic effects of PBDEs (Suvorov et al. 2011), which reported regulation of a limited number of thyroid responsive genes in rat brain and liver after exposure to 2,2',4,4'-tetrabromo diphenylether (BDE47). Due to the tractability for genomics, research mice were considered to be a suitable model to use for this study.

The objective of the present study was to evaluate the possible adverse effects of exposure to BDE47 during development, including both the gestational and lactational transfer from mouse dam to offspring via the placental circulation and via breast milk. The exposure period and route of exposure are highly relevant to humans. Overt clinical toxicity was not expected with this approach; hence, the use of sensitive early markers was imperative.

Furthermore, the study aimed to examine whether any ameliorating effect of nutrients could be detected with a maternal high-fish diet. Brain and tissue accumulation of BDE47, global cerebral gene expression, physical and neurobehavioural development and spontaneous behaviour were evaluated in maternally exposed murine offspring. The liver enzymes responsible for the major part of mammalian xenobiotic metabolism are often induced by the presence of the compounds they metabolise, including BDE47 (Sanders et al. 2006), and are widely used as markers of toxic responses. The transcriptional regulation of the hepatic enzymes, Cyplal, Cyp2b10, and Cyp3all was therefore assessed as a measure of the general toxic response to the current exposure to BDE47.

\section{Materials and methods}

The experiment and the animal facilities were approved by the National Animal Research Authority (NARA/FDU, Norway).
Experimental feeds

Animals were exposed to BDE47 via the food to mimic human exposure. The experimental diets were produced in-house, according to the AIN-93G rodent diet to meet $1995 \mathrm{NRC}$ rat/mouse reproduction, gestation and lactation values (DYETs Inc. formulation 110800). In order to investigate the effects of nutritional differences, two sets of diets were produced, one with and one without fish included. Briefly, the casein-based diet used casein sodium salt (Sigma Aldrich Inc.) as the sole source of protein and soy-bean oil as the source of lipid. The experimental, fish-based diets had 15\% (per weight) inclusion of freeze-dried Atlantic salmon (Salmo salar), supplemented with casein and soy oil to meet the desired protein and fat contents, respectively. All diets contained $17 \%$ protein and $10 \%$ fat (per weight). The salmon was experimentally raised for the EUproject AQUAMAX (EU-Contract no. 016249-2) using maximum plant protein and vegetable oil substitution in the fish feed (Torstensen et al. 2008), which gave very low levels of contaminants in the fish (Berntssen et al. 2010).

To investigate the effects of BDE47, the diets were spiked with high purity BDE47 (Cambridge Isotope Laboratories, MA, USA, and Chiron AS, Norway). The crystalline BD47 was dissolved and diluted in 100\% dimethylsulfoxide (DMSO) to appropriate concentrations and added to the soy-bean oil of each experimental diet. DMSO was added to all feeds at a final concentration of $0.4 \mathrm{ml} / \mathrm{kg}$. Six diets were produced: casein control, casein low level, casein high level, fish control, fish low level and fish high level. The "low level" aimed at a BDE47 concentration two to three times higher than the concentration typically found in Norwegian farmed Atlantic salmon (Bethune et al. 2006). A previous study found that the background dietary intake of 7PBDEs in Norwegians was $1.1 \mathrm{ng} \mathrm{kg}$ $\mathrm{BW}^{-1}$ day $^{-1}$ (Knutsen et al. 2008). The low level exposure $(\sim 6 \mu \mathrm{g}$ BDE47/kg feed) would exceed the human background intake $\sim 2,000$ times when the $30 \mathrm{~g}$ mouse consumed $10 \mathrm{~g}$ feed/day during lactation, equal to $2 \mu \mathrm{g}$ BDE47/kg BW. The "high level" feed concentration $(\sim 1,900 \mu \mathrm{g}$ BDE47/kg feed) represented consumption of fish with high concentrations of BDE47 and was estimated to give a peak intake of $\sim 650 \mu \mathrm{g} \mathrm{kg} \mathrm{BW}^{-1}$ day $^{-1}\left(\sim 1.4 \mu \mathrm{mol} \mathrm{kg} \mathrm{BW}{ }^{-1}\right.$ day $\left.^{-1}\right)$ for a $30-\mathrm{g}$ mouse consuming $10 \mathrm{~g}$ feed/day during 
lactation. This would exceed the mean dietary sum PBDE intake by hobby fishermen frequently consuming fish from the heavily polluted Lake Mjøsa approximately 13,000 times (Thomsen et al. 2008). Food safety authorities have not agreed on tolerable weekly intake estimates for the non-coplanar, nondioxinlike compounds such as BDE47. The estimates of pup exposure $\left(\mu \mathrm{g} \mathrm{kg} \mathrm{BW}^{-1}\right.$ day $\left.^{-1}\right)$ were based on an $80 \%$ oral absorption efficiency of BDE47 (Staskal et al. 2005), a 20\% transfer rate in milk (Darnerud and Risberg 2006) and a mean litter size of six pups/litter. the "high level" used in the present study aimed at a daily or accumulated dose to the growing pups in the range of what has previously given effects on spontaneous behaviour after a single oral dose of $1.4 \mu \mathrm{mol} / \mathrm{kg} \mathrm{BW}$ to pups on PND10 (Eriksson et al. 2001). The pup exposure would vary based on maternal intake and lactational transfer, pup bodyweight and the number of pups per litter. The individual pup exposure was of less importance, as the litter was considered a statistical unit in all later analyses. The repeated exposure of pups was assumed to result in higher accumulated BDE47 exposure than the single exposure previously used (Eriksson et al. 2001), and thus, the exposure was expected to give measurable effects.

\section{Analyses of feeds}

Feeds were analysed for congeners (IUPAC nos. BDE28, BDE47, BDE99, BDE100, BDE153, BDE154 and BDE183) and hexabromo cyclododecane by gas chromatography/mass spectrometry (GC/ MS) according to previously described methods (Bethune et al. 2005). This method was adapted to quantify high concentrations of PBDE in feeds and tissues. The adaptations consisted of adding 40 times more internal standard to high level feeds than control feeds before the extraction to bring the concentration of internal standard into the same order of magnitude as the BDE47 in the sample. The extracts from high level samples were then diluted in $20 \mathrm{ml}$ nonane $(99 \%$ pure, Sigma-Aldrich) before injection into the GC to bring the concentrations down to the linear range of the standard curve. The procedure diluted congeners other than the added BDE47 below the limit of quantification (LOQ). To ensure similarity among feeds, nutrients were also quantified in each feed. Protein content was analysed via the combustion method determining total nitrogen, using a Leco FP528 and Leco Software (Leco Corp., MI, USA), according to the "Association of Official Analytical Chemists Official Method 992.15 for Crude Protein in Meat and Meat Products Including Pet Foods". Crude protein was calculated assuming that protein contains $16 \%$ nitrogen. Total fat content was determined gravimetrically using ethylacetate extraction (NS9402 1994). Fatty acid composition was analysed (Lie and Lambertsen 1991; Torstensen et al. 2008), and individual fatty acids were identified by known purified standards. Vitamin A (all-trans-retinol) was analysed by high performance liquid chromatography (HPLC) with a UV-detector $(325 \mathrm{~nm})$ according to Moren et al. (2002). Vitamin D3 was analysed according to Horvli et al. (1994). Vitamin E ( $\alpha$ tocopherol) was analysed by normal phase HPLC with fluorescence detection (excitation of $289 \mathrm{~nm}$ and emission of $331 \mathrm{~nm}$ ) according to Hamre et al. (2010). Heavy metals (arsenic, mercury, cadmium, lead and selenium) were analysed by inductively coupled plasma/MS (Julshamn et al. 2007).

\section{Animal exposure}

Sixty BALB/c mice were supplied by Taconic Inc, Denmark. The females $(n=48)$ were previously proven breeders (one to two litters). Females were randomly divided into experimental groups and housed three to four females per cage in large rat cages (Eurostandard Type IV) with environmental enrichment, under laboratory conditions of $23 \pm 1^{\circ} \mathrm{C}$, $55 \pm 5 \%$ relative humidity and $12: 12 \mathrm{~h}$ light/dark cycle. Lights were on 0800-2000 hours. Groups were randomly and evenly distributed within racks to compensate for environmental variation. Control feeds were given during acclimation and oestrus stimulus (total of 9 days). As pups are exposed to BDE47 via the placental circulation and through breast milk during lactation (Darnerud and Risberg 2006), spiked feeds were given from the first day of mating [gestation day (GD) 0] until the end of trial on postnatal day (PND)18 (Fig. 1). One male was mated with three to four females during 1 week ( about two oestrus cycles). Females were housed individually from GD16 through lactation to monitor individual litter development during lactation, and the feed intake during this period was also monitored individually. Spillage of the powdered feed was limited by 
Fig. 1 Experimental outline. Reproducing BALB/c mice were exposed to BDE47 during mating, gestation and lactation. Mice offspring were treated and handled from postnatal day (PND) 5 as indicated. GD Gestation day

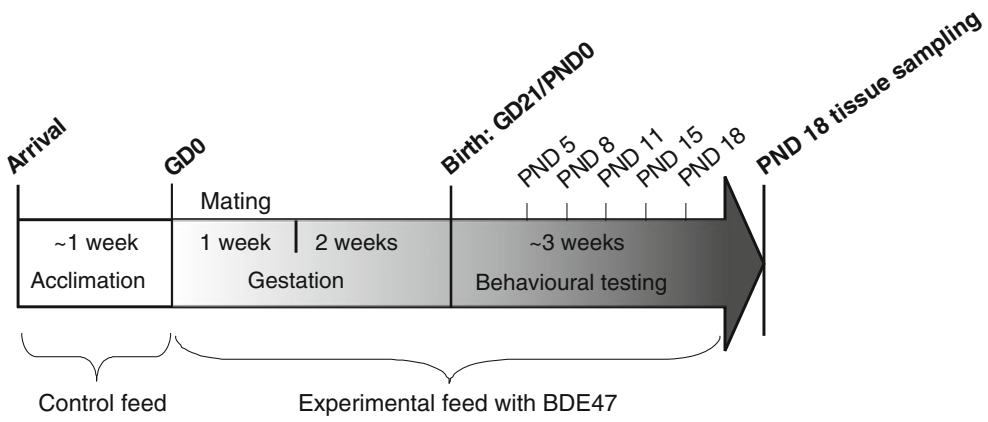

high-walled and stable food cups. Spillage was also monitored by sieving the bedding to remove the powdered feed during and after the trial. Cages were checked twice daily for litters from GD18, and the day of birth was denoted as PND0. Feed and water was given ad libitum, and the feed intake monitored for each mouse by weighing any uneaten food daily. The feed intake by individual dams was calculated in order to compare both nutritional status and group exposure to BDE47. During mating and the first two weeks of gestation, the food intake was averaged per cage. During individual housing from GD16, the individual feed intake was monitored. Dam feed intake during gestation represented feed consumption during the 21 days prior to PND0. Dam exposure during lactation ( $\mu \mathrm{g} \mathrm{kg} \mathrm{BW}{ }^{-1}$ day $^{-1}$ ) was calculated based on the monitored daily feed intake from PND0 to PND18 and the bodyweight on the last weighing during gestation (GD16).

The nests were left undisturbed until PND5 to avoid maternal aggression, which has been observed after disturbance of BALB/c as late as PND3 (Folven, pers. comm.). The term "litter size" therefore reflects the verified number of live pups on PND5, counted before sampling commenced. Large litters were reduced to five pups on PND5 both to obtain tissue for analyses and to reduce variation in the amount of feed consumed by the dams. Reducing the largest litters would also ensure adequate nutrition of all pups.

Physical development and neurobehavioural testing

Two random pups per litter were tested from 0800 to 1400 hours on PND5, PND8, PND11, PND15 and PND18 for physical and behavioural development by a single experimenter who was unaware of the group exposure. The behavioural tests were based on the so called Fox-battery (Fox 1965) with adjustments made according to Bignami (1996) and Folven et al. (2009). Tests were performed as described in Folven et al. (2009). Pups were weighed and observed for markers of physical development every day of testing. The behavioural test battery included righting reflex, foreand hind limb grasp and hang-climb ability (all tested on PND5-PND11), auditory startle reflex (PND5PND15), visual placing, cliff drop aversion and grip strength (all tested on PND15 and PND18) and hind limb splay (PND18 only). Pup and adult forelimb grip strength was tested on PND18 by a grip strength meter (San Diego Instruments Inc., San Diego, CA, USA). On PND18, pups and adults were tested for spontaneous behaviour and emotional reactivity in an elevated plus maze (San Diego Instruments Inc., San Diego, CA, USA), assessing distance travelled, time spent resting, number of zone crossings and permanence time in each zone. A modification in the startle reflex test consisted in using a metal click-box was to produce a sudden, sharp noise for the auditory startle reflex. For the hang-climb test, graded levels of climbing were scored in the following manner: $0=$ no hang, $1=1-14 \mathrm{~s}, 2=15-29 \mathrm{~s}, 3=30-44 \mathrm{~s}, 4=45-$ $59 \mathrm{~s}, 5=>60 \mathrm{~s}, 6=$ successfully moving and replacing two limbs, $7=$ successfully replacing three limbs and $8=$ successfully replacing all four limbs.

Statistical analyses of animal development and behaviour

The statistical methods used kept the litter as the experimental and statistical unit as recommended in testing of multiparous species (Piegorsch and Haseman 1991; Holson and Pearce 1992).

All comparisons of reflex scores were initially based on the mean litter score (Supplementary Table A) using either one-way ANOVA or the non- 
parametric Kruskal-Wallis followed by pair-wise testing with Mann-Whitney $U$ test, according to previously published methods (Folven et al. 2009). Homogeneity of variance was assessed by Levene's test, and normal distribution was assessed by ShapiroWilk's test of normality. Normally distributed data with homogeneous variance were compared using the parametric one-way ANOVA (the Brown-Forsythe test) and Student's $t$ test. Data that were not normally distributed, or had non-homogeneous variance, were tested by Kruskal-Wallis test for independent samples and Mann-Whitney $U$ pair wise comparison (with twotailed exact test) (SPSS v 15.0 for windows; SPSS Inc, Chicago, IL, USA). Data from the elevated plus maze were analysed as according to Folven et al. (2009).

The reflexes "righting" and "hind limb grasp" appeared to be influenced by litter size. The mean litter score approach does not allow correction for the influence of litter size; thus, a generalised linear model (GLM) with binomial distribution was employed using the statistical software "R" v.2.9.0 (R Development Core Team 2009) in an attempt to delineate the effects of the litter size. The GLM model assessed how the response characteristics were influenced by the independent predictors "diet" (fish or casein), "concentration" (control, low, high) and "litter size" (1-11 pups), and their interactions. In the GLM model, each dam was considered an independent observation, and each pup tested was a trial under that observation. The response variable was the number of successful scores in relation to the number of tested pups per litter. Ideally, the GLM method requires behavioural testing of more than two pups per litter, and the method was therefore only applied to the behavioural tests where significant difference was found when using the mean litter score.

A generalised least square regression (GLS) was used to model feed intake by dams in relation to BDE47 level, diet (fish or casein) and litter size. A linear mixed effect model (LME) (Pinheiro and Bates 2000) was used to investigate the differences in pup body weight and hepatosomatic index (HSI), with the dam as the random variable. GLM, LME and GLS adjust for the uneven variance (heteroscedascity) of the residuals. The statistical models were selected from backward elimination of full three-way interactions, deleting non-significant terms. The methods were based on previous publications, presented in
Zuur et al. (2009). Post hoc test was Tukey's honestly significant difference, where applicable. Significance levels were set at alpha $=0.05$ for all methods.

\section{Tissue sampling}

Animals were anaesthetised using a ventilated chamber Univentor 400 (Univentor Ltd., Malta) with 4\% gaseous Isofluran and $\sim 400 \mathrm{ml} / \mathrm{min}$ airflow, and then euthanised by cervical dislocation. The brain and liver were quickly removed with RNAse free equipment and weighed. HSI is defined as (liver weight/body weight) $\times 100$.

Tissues for RNA extraction were frozen in liquid nitrogen and stored at $-80^{\circ} \mathrm{C}$ until processing. Tissue for analysis of PBDE concentrations were frozen at $-20^{\circ} \mathrm{C}$ and analysed by GC/MS (Bethune et al. 2005) with modifications as described for the analysis of feeds. Tissue samples for PBDE analysis were thawed, weighed and manually homogenised before extraction.

\section{Microarray analysis}

Total RNA was extracted from the right hemisphere of the brain from female pups (PND18), using Trizol reagent (Invitrogen, Life Technologies, Carlsbad, CA, USA) combined with the Qiagen RNeasy-Mini kit (Qiagen, Mississauga, ON, Canada). Extracted RNA was stored at $-80^{\circ} \mathrm{C}$ until further processing. RNA purity was assessed using Nanodrop ND-100 UV-Vis Spectrophotometer (Nanodrop Technologies, Wilmington, DE, USA), and RNA quality and integrity were evaluated using the Agilent 2100 Bioanalyzer and the RNA 6000 LabChip kit (Agilent Technologies, Palo Alto, CA, USA). To ensure good quality of further analyses, only RNA of high purity and integrity were included in the study. RNA purities (260:230 ratios) were above 2, and RNA integrity numbers (RIN) were between 9.4 and 10. Superscript III ${ }^{\mathrm{TM}}$ Indirect labelling system (Invitrogen), Cy5 and Cy3 (Mono-Reactive Dye Pack, Amersham Biosciences) were used to produce, purify and fluorescence-label aminoallyl complementary DNA (cDNA) from $15 \mu \mathrm{g}$ of total RNA, according to the Invitrogen protocol for indirect labelling. A reference cDNA pool was made from $15 \mu \mathrm{g}$ RNA from all samples. Anchored primer (Oligo-dT) was used for messenger RNA transcription. Reference (Cy3) and sample (Cy5) labelled cDNA were hybridised to micro- 
arrays spotted with 35,852 65-mer oligonucleotide probes, representing close to 25,000 genes and 38,000 gene transcripts (mouse OpArray, 4.0, Operon, Huntsville, AL, USA), according to the manufacturers protocol. Images of hybridised slides were captured using ScanArray ${ }^{\circledR}$ Express (Perkin Elmer Inc., Waltham, MA, USA).

Bioinformatics and statistical analyses of microarray data

After initial scanning of slides, background corrected spot intensities were identified using the Bluefuse software (BlueGnome Ltd., Cambridge, UK) and data exported, including data on Bluefuse spot confidence and probabilities of biological signal scores. Expression-data was then imported into $\mathrm{R}$ using the Bioconductor package Limma (Smyth et al. 2005). Spots with $<0.3$ score from Bluefuse on probability of biological signal for each channel in at least $70 \%$ of arrays were filtered from further analysis. Colour intensity plots for both channels (MA plots) and between-array boxplots were used to visually assess array quality. Arrays with severe hybridisation or printing artefacts were removed. After quality filtering, the remaining arrays for each condition included casein $\operatorname{control}=5$, fish $\operatorname{control}=4$, fish low level $=2$, casein high level=4, and fish high level=3. Each sample represented one individual female pup on PND18. No siblings were used for analysis or pooled for hybridisation. These remaining 18 arrays with 22,476 quality assured spots were used for withinarray LOESS normalisation and between-array median scaling. Differentially expressed genes (all compared to casein control) were identified for each condition by a linear model with array weighting in Limma (Smyth 2004; Ritchie et al. 2006). Due to the small group size in the fish low group after quality filtering, both low level groups were excluded from further analyses. Benjamini-Hochberg multiple testing correction was applied to unadjusted $P$ values to identify the false discovery rate (FDR) of each gene (Benjamini and Hochberg 1995).

Functional clustering and selection of genes for RT-qPCR validation

Lists of differentially expressed genes (in relation to casein control) were imported into the Ingenuity
Pathway Analysis (IPA v 8.0, Ingenuity Systems Inc.) to determine functional pathways affected by the BDE47 exposure. Direct and indirect relationships among genes from the Ingenuity Knowledge Base, limited to mammalian "central nervous system cell lines" and "the nervous system", were used to explore pathways and networks related to the regulated genes, based on guidelines for Best Practice by IPA. Initial filter criteria for genes to be included in networks were $\log 2$ ratio of $\pm 0.85 \quad(\sim 1.8$-fold change) and $\mathrm{FDR} \leq 0.05$. This filtering returned no genes eligible for networks and pathways from the present study, indicating limited cerebral gene-expression regulation by BDE47. In order to produce a list of genes for further examination in IPA, enabling selection of genes of interest likely to be affected by BDE47, the statistical stringency was relaxed. Genes were now filtered based on $\log 2$ ratio as low as \pm 0.58 (fold change, $\sim 1.5$ ) and FDR $=0.2$. This produced a list of 52 network eligible genes and 273 genes eligible for functions and pathways, at the cost of a lower confidence. The genes that passed were from the casein high level group only. No genes from the fish high level or fish control groups passed this filtering, indicating minimal regulation of genes in fish high level and fish control groups. Genes from the fish high level were finally filtered using a coarse filter of FDR 0.4 in order to produce a gene list for inspection and visualisation of results in IPA, with additional loss of confidence in these genes.

The main criteria for genes to be selected for validation by RT-qPCR were significant regulation in this study and relevance to neuronal development and function. Genes present in central networks and pathways in the IPA analyses were of primary interest. Genes found in similar in vitro and in vivo studies performed by these groups (Carroll 2010) were considered of interest. The five genes CXCR4, Rara, TRP53, Cyp1a1, Cyp2b10 and Cyp3a11 were also chosen based on the biological functions of their gene products in neurodevelopment and toxicology. The chemokine receptor CXCR4 has been found to be involved in brain homeostasis and central nervous system (CNS) development and plays an important role in neural migration (reviews by Bajetto et al. 2001; Ransohoff et al. 2007). Retinoic acid receptor alpha (Rara) was chosen based on the known role of retinoids in morphogenesis, development and reproduction, as 
well as being a biomarker for environmental pollutants (review by Novak et al. 2008). TRP53 has been found to have a central role in carcinogenesis and chromosome repair (Strachan and Read 1999; Verheyde et al. 2006). Cyplal, a well-known target gene in toxicology and a toxicity biomarker for the Aryl hydrocarbon receptor (AhR) (Hu et al. 2007), was included as a negative control, as BDE47 has been shown to not activate AhR in liver (Chen et al. 2001; Behnisch et al. 2003; Sanders et al. 2005; Peters et al. 2006). Cyp $2 b 10$ and Cyp3a11 have been shown to be activated in liver by non-coplanar PBDEs (Sanders et al. 2005; Pacyniak et al. 2007) and were also included for RT-qPCR on both liver and brain cDNA to elucidate the induction of these genes in response to BDE47.

Two additional thyroid-responsive genes, nuclear factor $1 \mathrm{~B}(N f 1 B)$ and insulin-like growth factor binding protein $(\operatorname{Ig} f 2 b)$, were found to be regulated in both liver and brain after exposure to BDE47 in a recent study (Suvorov et al. 2011) and were examined by RT-qPCR for cross-study comparison. In addition to thyroid responsiveness (Suvorov et al. 2011), $\operatorname{Igfbp} 2$ is associated with regulation of cell growth and signal transduction and has been shown to be responsive to retinoic acid (Chambery et al. 1998), while $N f I B$ is also associated with DNA replication and adenomas (Geurts et al. 1998).

\section{RT-qPCR of selected genes}

RNA for RT-qPCR was extracted from the same snapfrozen brain tissue homogenate that was used for microarray RNA extraction. Total RNA was extracted from frozen homogenate in $1 \mathrm{ml}$ Qiazol and DNase treated using BioRobot EZ1 Workstation (Qiagen) as specified by the manufacturer. For livers, the RNAs from 18-day-old male and female pups were extracted with Trizol as described for brain RNA. Liver RNA was DNase treated using DNA-free ${ }^{\mathrm{TM}}$ (Ambion). Quality control was performed as described for microarray RNA. RT-qPCR was performed as described by Olsvik et al. (2009). A modification was that the serial dilution standard curve was run in duplicate from 31 to $125 \mathrm{ng}$ to fit all samples into one 96-well plate. The reaction volume for the reverse transcription reaction (RT-PCR) was $50 \mu \mathrm{l}$. The resulting cDNA was diluted to $150 \mu \mathrm{l}$, and $2.5 \mu \mathrm{l}$ of the diluted cDNA was transferred to a 384-well reaction plate and the qPCR run in $10 \mu$ l reactions on a LightCycler 480 Real-Time PCR System (Roche Applied Sciences, Basel, Switzerland). The qPCR was achieved with 10-min activation and denaturing step at $95^{\circ} \mathrm{C}$, followed by 45 cycles of a $15-\mathrm{s}$ denaturing step at $95^{\circ} \mathrm{C}$ and a 60 -s annealing and elongation step at $60^{\circ} \mathrm{C}$. A melt curve analysis was performed for every gene. Reference genes for the RT-qPCR were selected according to MIQE guidelines (Bustin et al. 2009). Three reference genes (ATP5B, CANX and RPL13A) were selected from the geNorm $^{\text {TM }}$ housekeeping gene selection kit (catalog no. ge-Sy-6-mo, PrimerDesign Ltd, Southampton, UK) by use of GeNorm (v3.5). Relative quantification of genes was performed using the $\Delta \Delta$-Ct method, based on a $\mathrm{Ct}$ value obtained from the second derivative maximum of the curve. Two samples with outlying values for several genes of interest, and with large standard deviations among triplicates, were removed. Final sample sizes for statistical analysis of RT-qPCR data were the following: casein control= 6, fish $\operatorname{control}=5$, casein high $=4$ and fish high $=4$. Relative expression levels were compared using Kruskal-Wallis test of independent samples, followed by Mann-Whitney $U$ pair wise comparisons (exact test). Relative expression (evaluated by SYBR green assays) was repeated in an independent laboratory. A selection of genes was also tested using an additional hydrolysis probe assay (TaqMan $\left.{ }^{\circledR}\right)$.

\section{Results}

Comparability of diets

Analyses of the feeds verified that the levels of protein, fat and vitamins were the same in fish- and casein-based diets (Haave et al. 2011) and that the metal concentrations were similar in all diets. For most cases, the metal concentrations were close to or below the LOQ (data not shown). Paired diets had comparable BDE47 concentrations (Table 1). BDE47 was also the most prevalent congener in the control feeds, although at very low concentrations. BDE99 was present at low levels in all diets, whereas all other congeners analysed were only present in the fishbased diets at low levels (Supplementary Table B), underlining that despite the efforts to produce a clean fish (Torstensen et al. 2008; Berntssen et al. 2010), these substances are omnipresent in the environment 
Table 1 Feed concentration of BDE47, body weight, reproductive output, feed intake and ingested dose by reproducing dams fed BDE47 in a fish- or a casein-based diet during gestation and lactation

\begin{tabular}{llllllllll}
\hline Diet (n) & $\begin{array}{l}\text { BDE47 } \\
\text { ng/g feed }\end{array}$ & $\begin{array}{l}\text { Initial BW } \\
\text { dams (g) }\end{array}$ & $\begin{array}{l}\text { Final BW } \\
\text { dams (g) }\end{array}$ & $\begin{array}{l}\text { Repr. succ. } \\
(\%)\end{array}$ & $\begin{array}{l}\text { Litter size } \\
(\min -\mathrm{max})\end{array}$ & $\begin{array}{l}\text { Intake } \\
\text { gestation } \\
(\mathrm{g} / \text { day) }\end{array}$ & $\begin{array}{l}\text { Intake } \\
\text { lactation } \\
(\mathrm{g} / \text { day) }\end{array}$ & $\begin{array}{l}\text { Gestation dose } \\
\left(\mu \mathrm{kg} \mathrm{BW}^{-1} \mathrm{day}^{-1}\right.\end{array}$ & $\begin{array}{l}\text { Lactation dose } \\
\left(\mu \mathrm{kg} \mathrm{BW}^{-1} \mathrm{day}^{-1}\right)\end{array}$ \\
\hline CC (7) & $0.40 \pm 0.03(3)$ & $30.6 \pm 0.8$ & $32.1 \pm 0.4$ & 70 & $6.1(1-10)$ & $4.0 \pm 0.1$ & $7.5 \pm 0.6$ & $0.05 \pm 0.00$ & $0.08 \pm 0.00$ \\
FC (6) & $0.35 \pm 0.03(3)$ & $29.0 \pm 0.8$ & $33.1 \pm 0.8$ & 75 & $5.3(2-9)$ & $4.0 \pm 0.1$ & $7.6 \pm 0.4$ & $0.04 \pm 0.00$ & $0.07 \pm 0.00$ \\
CL (3) & $6.63 \pm 1.06(3)$ & $31.1 \pm 2.3$ & $33.3 \pm 1.6$ & 38 & $7.0(4-11)$ & $4.1 \pm 0.1$ & $7.9 \pm 0.6$ & $0.78 \pm 0.06$ & $1.41 \pm 0.17$ \\
FL (5) & $5.64 \pm 0.70(3)$ & $30.2 \pm 0.9$ & $33.6 \pm 1.3$ & 63 & $5.2(1-8)$ & $4.0 \pm 0.1$ & $7.6 \pm 0.7$ & $0.66 \pm 0.02$ & $1.18 \pm 0.12$ \\
CH (6) & $1900 \pm 74(3)$ & $30.0 \pm 1.0$ & $31.8 \pm 0.7$ & 75 & $7.0(4-10)$ & $4.0 \pm 0.0$ & $7.8 \pm 0.3$ & $227 \pm 8$ & $421 \pm 22$ \\
FH (7) & $1946 \pm 129(3)$ & $29.4 \pm 1.0$ & $32.4 \pm 1.0$ & 88 & $5.3(3-9)$ & $4.0 \pm 0.1$ & $7.0 \pm 0.6$ & $243 \pm 8$ & $402 \pm 32$ \\
\hline
\end{tabular}

Data are presented as mean \pm SEM of analysed or calculated values. Sample size in brackets. Initial BW (bodyweight) $=\mathrm{BW}$ after acclimation in females that produced live pups, final $\mathrm{BW}=\mathrm{BW}$ at the end of weaning. Repr. succ. $=$ successful reproduction in relation to the number of mated females. Feed intake and dose during gestation (GD0-21) and lactation was based on daily monitoring of feed intake. $C C$ Casein control; $F C$ fish control; $C L$ casein low level; $F L$ fish low level; $C H$ casein high level; $F H$ fish high level

and in food. However, concentrations of all other contaminants than BDE47 in the final feeds were considered sufficiently low to disregard any toxicity arising from their presence.

\section{Reproduction and physical development}

No overt symptoms of toxicity or consistent differences in HSI in pups or dams were found throughout the trial. After acclimation, there were no consistent PBDE exposure-related group differences in body weight among dams. No group differences were seen in mean feed or PBDE intake, litter size or reproductive success among dams (Table 1). Dam feed intake during lactation was significantly correlated with number of pups born (Pearson's product-moment correlation $\left.r^{2}=0.84, p<0.001\right)$, but feed intake was not influenced by a fish- or casein-based diet or the concentration of BDE47. Pup body weight was negatively correlated to litter size throughout lactation (LME, $p<0.001$ ), but was not influenced by the BDE47 exposure of the dam. Although litters were reduced to five on PND5, the pup size remained dependent on initial litter size (PND5) until PND18, which meant that no compensatory growth or weight gain was seen after culling on PND5. The nutritional status of pups from all litters was considered good at all times.

Pup tissue concentrations of BDE47 reflected the maternal intake (Haave et al. 2011). The mean concentration of BDE47 in brains on PND18 were $80 \pm 3 \mathrm{ng} / \mathrm{g}$ ww in the casein high group $(n=6)$ and
$62 \pm 9 \mathrm{ng} / \mathrm{g}$ ww in the fish high group $(n=7)$. Casein control and fish control both had PBDE47 concentrations in brain below $0.1 \mathrm{ng} / \mathrm{g}$ ww $(n=2$, two pools of three samples analysed per group; Fig. 2). The level of BDE47 in brains from the fish high group was similar to casein high $(p<0.1)$, although the levels of BDE47 in liver, fat and stomachs were consistently lower in the groups fed the fish-based diets than that in the casein-based diets (Haave et al. 2011).

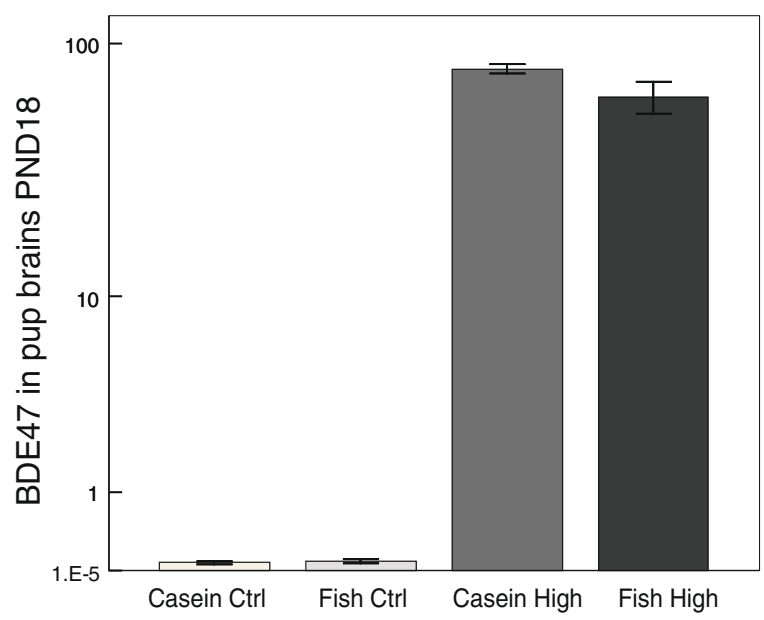

Fig. 2 Concentration of BDE47 in brains. Mean $( \pm$ SEM) concentration of BDE47 (ng/g wet weight) analysed in brains from mouse pups on PND18. The pups were maternally exposed to diets containing $\sim 0.4 \mu \mathrm{g}$ BDE47 $/ \mathrm{kg}$ feed (control) or $\sim 1,900 \mu \mathrm{g}$ BDE47/kg feed (high level) throughout gestation and lactation in a fish- or a casein-based feed. Casein Ctrl (control) and Fish Ctrl, $n=2$; two pools of tissue with three litters per pool; casein high level, $n=6$; fish high level, $n=7$ 


\section{Behavioural tests}

The speed of development and the age of occurrence of fully developed reflexes did not differ among groups. The examination of the righting reflex and hind limb grasp reflex showed significantly lower reflex development in the fish high group after the initial comparison of mean litter scores. As the reflexes seemed affected by litter size, the statistical analyses were repeated using GLM, correcting for litter size. The GLM model supported the finding that level of BDE47 exposure significantly affected righting reflex on PND8 $(p<0.05)$, also when correcting for litter size. However, the post hoc assessment showed that the righting reflex was only marginally lower in BDE47 "high level" groups compared to controls $(p=0.055)$. In contrast, BDE47 exposure did not affect hind limb grasp significantly, after the correction for litter size using the GLM model. There were no further differences in the early reflex development scores, in physical development, grip strength or hind limb splay in pups in relation to BDE47 exposure. Detailed investigations failed to discern any differences in spontaneous behaviour and reactivity in the elevated plus maze.

Microarray analysis and qPCR validation

The gene list from casein high (filtered on $\log 2$ ratio of $\sim 0.58$ and $\mathrm{FDR}<0.2$ ) was analysed in IPA and used for selection of genes for qPCR validation (Table 2). Genes from the fish high group were filtered using a coarse filter of FDR 0.4 in order to produce a gene list for import in IPA. Many of the

Table 2 Relative expression values for genes in the casein high level group compared to casein control

\begin{tabular}{|c|c|c|c|c|c|}
\hline \multirow[t]{2}{*}{ Entrez ID } & \multirow[t]{2}{*}{ Gene name } & \multicolumn{2}{|l|}{ Microarray } & \multicolumn{2}{|l|}{ RT-qPCR } \\
\hline & & Log2 ratio & FDR & $\log 2$ ratio & $\begin{array}{l}\text { Exact sign } \\
\text { ( } p \text { value })\end{array}$ \\
\hline 11423 & Acetylcholinesterase (Ache) & -0.75 & 0.13 & -0.13 & 0.48 \\
\hline 12064 & Brain derived neurotrophic factor $(B d n f)$ & 0.73 & 0.12 & 0.04 & 0.61 \\
\hline 12767 & Chemokine $\left(\mathrm{C}-\mathrm{X}-\mathrm{C}\right.$ motif) receptor $4(C X C R 4)^{\mathrm{a}}$ & 0.38 & 0.36 & -0.16 & 0.17 \\
\hline 13385 & Discs, large homolog 4 (Drosophila) $(D \operatorname{lgh} 4)^{\mathrm{a}}$ & -0.25 & 0.51 & 0.08 & 0.48 \\
\hline 14810 & Glutamate receptor, ionotropic, NMDA1 (zeta 1) (Grin1) & -0.99 & 0.09 & 0.09 & 0.76 \\
\hline 14645 & Glutamate-ammonia ligase (glutamine synthetase; Glul) & 1.82 & 0.11 & 0.29 & 0.02 \\
\hline 14828 & Heat shock protein $5(H S P 5)^{\mathrm{a}}$ & 0.49 & 0.27 & 0.13 & 0.35 \\
\hline 3485 & Insulin-like growth factor binding protein $2(\operatorname{Ig} f b p 2)^{\mathrm{a}}$ & 0.43 & 0.2 & 0.63 & 0.04 \\
\hline 67405 & Neurotensin $(N t s)$ & 1.00 & 0.12 & -0.05 & 0.76 \\
\hline 4781 & Nuclear factor I/B $(N f 1 B)^{\mathrm{a}}$ & -0.14 & 0.773 & -0.27 & 0.17 \\
\hline 18754 & Protein kinase $\mathrm{C}$, epsilon (Prkce) & -1.56 & 0.09 & 0.17 & 0.17 \\
\hline 19401 & Retinoic acid receptor, alpha $(\text { Rara })^{\mathrm{a}}$ & -0.08 & 0.87 & -0.52 & 0.04 \\
\hline 105727 & Solute carrier family 38 , member 1 (Slc381) & -0.59 & 0.12 & -0.15 & 0.26 \\
\hline 22059 & Transformation related protein $53(T R P 53)^{\mathrm{a}}$ & 0.57 & 0.33 & 0.11 & 0.17 \\
\hline 1543 & Cytochrome P450, family 1 , subfamily a, polypeptide $1(\text { Cypla } 1)^{\mathrm{a}}$ & n.d. & n.d. & n.d. & n.d. \\
\hline 1555 & Cytochrome P450, family 2 , subfamily 2 , polypeptide $10(\text { Cyp } 2 \text { b10 })^{\mathrm{a}}$ & n.d. & n.d. & n.d. & n.d. \\
\hline 13112 & Cytochrome P450, family 3, subfamily a, Polypeptide $11(\text { Cyp } 3 a 11)^{\mathrm{a}}$ & 0.3 & 0.5 & n.d. & n.d. \\
\hline
\end{tabular}

The genes were selected for validation by RT-qPCR. Genes were selected based on the statistical comparison of relative expression values in casein high level versus casein control or based on biological function and presence in central IPA networks. Microarray data represent $\log 2$ ratio compared to casein control. RT-qPCR data represent relative expression values transformed to log2 ratio for comparison to microarray data. Significance values from statistical analyses of RT-qPCR data were obtained by Mann-Whitney $U$ comparison of relative expression values (exact test)

FDR False discovery rate; $n$.d. not detected, i.e. low expression values in microarrays and/or RT-qPCR

${ }^{a}$ Selected based on presence in central networks, or relevant biological functions and not from regulation according to the microarray analysis 
same genes were recurring in top IPA networks and pathways from both casein high level and fish high level (Table 3). Moreover, the top functional network from both casein and fish high level were termed "cell-to-cell signalling and interaction, nervous system development and function, and behaviour" (Table 3). Additionally, "neurological disease" was at the top of the IPA list of "related diseases and disorders" for the casein high group (34 associated genes, $p<0.05$ ). One of the main significant canonical pathways in IPA was the glutamate signalling pathway. The gene $(G l u l)$ for the converting enzyme (Glutamate ammonia ligase) as well as synaptic transporters of glutamate (Slc38-1) and downstream receptors for glutamate in ion-channels (Grin1) were regulated in the microarray analysis. However, RTqPCR confirmed only the regulation of Glul (Fig. 3a and Table 2). The separate validation of a selection of genes by TaqMan ${ }^{\circledR}$ probes gave no conflicting results. Glul was among the separately validated genes.

Glutamate-ammonia ligase $(G l u l)$, which is central to the glutamate signalling pathway, was one of the most highly regulated genes in microarray analysis (Table 2). Generally, the RT-qPCR results of selected genes supported the original and more stringent filtering of microarray data $(\log 2$ ratio of $0.85, \mathrm{FDR}=$ 0.05), which had suggested no cerebral geneexpression changes among groups. Among the five genes that were chosen based on their relevant biological function and previously shown relation to

Table 3 The top functional networks from microarray analysis of cerebral gene expression in murine offspring exposed to BDE47 during brain development

\begin{tabular}{|c|c|c|c|c|}
\hline & Top Functions & $\begin{array}{l}\text { Genes in network } \\
\text { Upregulated, } \\
\text { downregulated, } \\
\text { added by IPA }\end{array}$ & IPA Score & $\begin{array}{l}\text { \# Focus } \\
\text { Molecules }\end{array}$ \\
\hline 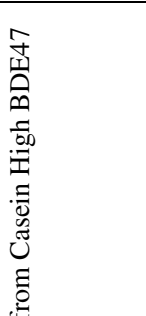 & $\begin{array}{l}\text { Cell-To-Cell } \\
\text { Signalling and } \\
\text { Interaction, Nervous } \\
\text { System } \\
\text { Development and } \\
\text { Function, Behaviour }\end{array}$ & $\begin{array}{l}\text { CDH2, CHN1 (includes EG:108699) } \\
\text { EPHA4, HTT, KLF4, S100A4 } \\
\text { ACHE, APOE, APP, CDK5, } \\
\text { CDK5R1, CTNNB1, DLG4, DPYSL2 } \\
\text { DRD1, FOS, GRIK2, GRIN1, } \\
\text { GRIN2A, GSR, ITPR1, MAPK1, } \\
\text { MAPK3, PEA15, RELA, SLC1A1, } \\
\text { SLC1A2, SYN1, SYP, XBP1 } \\
\text { GRIN3A, IL6, IL1B, NOS1, NTF3 }\end{array}$ & 11 & 17 \\
\hline 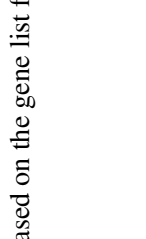 & $\begin{array}{l}\text { Nervous System } \\
\text { Development and } \\
\text { Function, } \\
\text { Behaviour, } \\
\text { Digestive System } \\
\text { Development and } \\
\text { Function }\end{array}$ & $\begin{array}{l}\text { BDNF, NTS } \\
\text { AP2A2, APP, ARC, CACNG7, FOS } \\
\text { FYN, GAL, GRIA1, GRIA2, LEP, } \\
\text { NR4A1, POMC, SNAP25, VAMP2 } \\
\text { CRH, IL1B }\end{array}$ & 6 & 9 \\
\hline 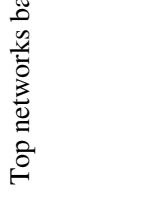 & $\begin{array}{l}\text { Developmental } \\
\text { Disorder, } \\
\text { Psychological } \\
\text { Disorders, } \\
\text { Neurological } \\
\text { Disease }\end{array}$ & $\begin{array}{l}\text { GABRG2 } \\
\text { GABRA1, GABRA6, GABRD, } \\
\text { PRKCE } \\
\text { none }\end{array}$ & 2 & 3 \\
\hline 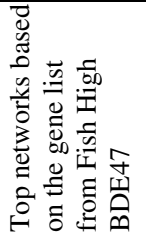 & $\begin{array}{l}\text { Cell-To-Cell } \\
\text { Signalling and } \\
\text { Interaction, Nervous } \\
\text { System } \\
\text { Development and } \\
\text { Function, Behaviour }\end{array}$ & $\begin{array}{l}\text { DRD1, HTT, KLF4 } \\
\text { APP, CDK5, CTNNB1, CTTN, DLG4, } \\
\text { GRIN1, GRIN2A, GRIN2B, MAPT, } \\
\text { PAK1, SLC1A2, SYP } \\
\text { none }\end{array}$ & , & 5 \\
\hline
\end{tabular}

Red and green gene names in bold font means that the gene was regulated according to the filter criteria. A gene name in normal font means that the gene was present in the list of regulated genes but did not pass the filter criteria: $\log 2$ ratio of \pm 0.58 compared to controls and FDR $<0.2$ (casein high level group) or FDR $<0.4$ (fish high level group). The functional analyses were generated through the use of Ingenuity Pathways Analysis (Ingenuity ${ }^{\circledR}$ Systems, http://www.ingenuity.com) 
Fig. 3 Relative expression of Glul, Rara and Igfbp2 in brains. Relative expression levels in RT-qPCR of a glutamate ammonia ligase $(G l u l)$, b retinoic acid receptor alpha (Rara) and insulinlike growth factor binding protein 2 (Igfbp2) in female mouse pup brains on PND18. Casein control, $n=6$; fish control, $n=5$; casein high level, $\mathrm{n}=4$; fish high level, $n=4$. Ctrl Control. * $p<$ 0.05 , significantly different from casein control (Mann-Whitney $U$, exact significance test). ${ }^{\#} p<0.1$, trend from fish high level (Mann-Whitney $U$, exact significance test)

toxic responses, only Rara was shown by RT-qPCR to be significantly downregulated in casein high level compared to casein control ( $p<0.04$, Fig. 3b). However, the fold change for Rara was low (Table 2). Expression data for Rara from microarray analysis did not pass filtering in IPA (Table 2), indicating that the expression change for Rara was minor and possibly at or below the noise level for the microarray analysis in this study. Cyp1a1, Cyp2b10 and Cyp3a11 were not significantly regulated or even consistently expressed in the brains according to both microarrays and RT-qPCR analyses.

The previous finding of two regulated thyroid responsive genes $(I g f b p 2$ and $N f 1 B)$ in liver and brain (Suvorov et al. 2011) were tested by RT-qPCR and were in part supported by the present study. Igfbp2 showed significant upregulation in brain in Casein High level compared to casein control in qPCR (Table 2, Fig. 3c). Also in the microarray analysis, the gene was upregulated $(\log 2$ ratio, $0.43 ; \mathrm{FDR}=$ 0.2 ), but did not pass the filtercriteria. There was no regulation of $I g f b p 2$ in fish high level. $N f 1 B$ was not significantly regulated in the brain after BDE47 exposure (Table 2), but showed a slightly lower expression in casein high than in casein control in RT-qPCR. Also in microarrays, the gene for NfIB was slightly downregulated ( $\log 2$ ratio, -0.14$)$, but did not pass the filter in IPA.

To evaluate the general toxic response to BDE47 with the current exposure, the regulation of gene expression for metabolic enzymes were analysed in liver tissue of the pups. Although high concentrations of BDE47 were detected in liver tissues, expression of Cyp2b10 and Cyp3a11 did not change in BDE47 exposed groups compared to controls (data not shown). Cyplal was not significantly regulated among groups, but showed trends to lower expression in fish control compared to casein control. Cyplal was highest expressed in casein control and was, hence, not induced by BDE47 with the current exposure (Fig. 4).
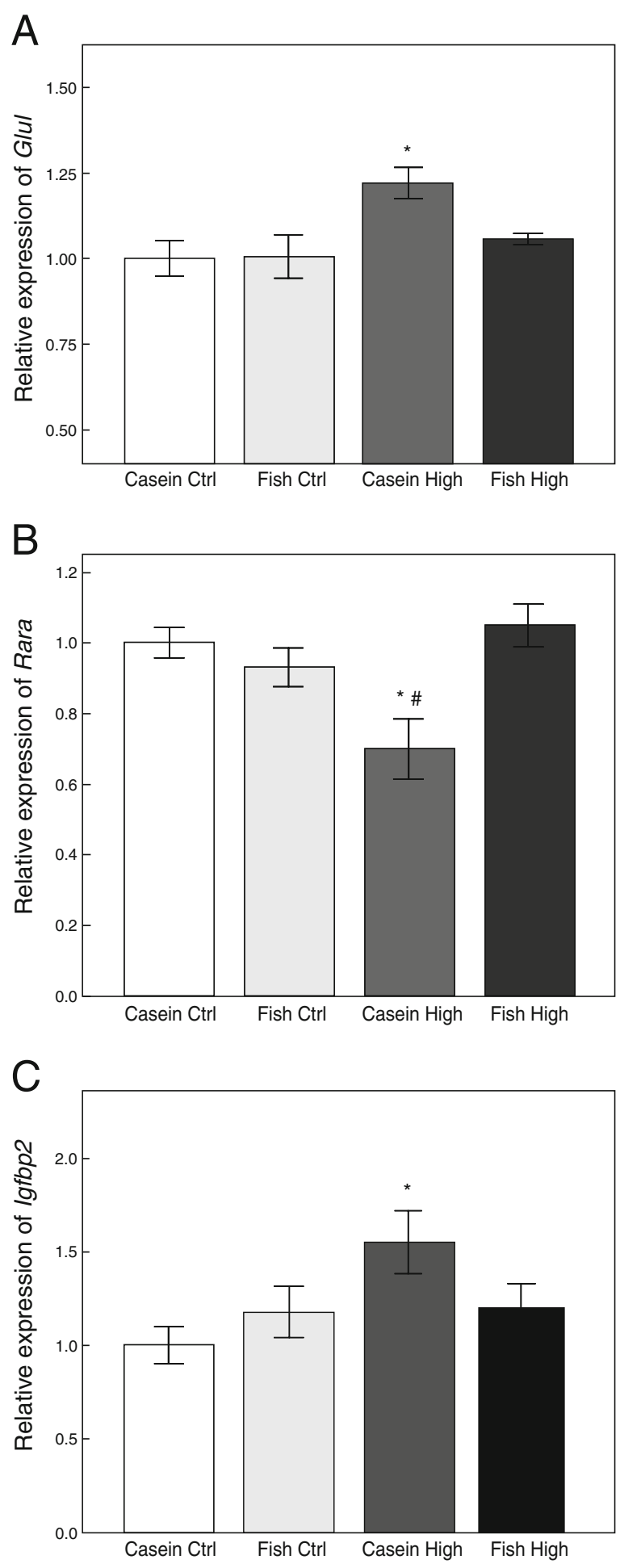

Similarly, the casein control group had the highest mean expressions of $I g f b p 2$ and $N f I B$ in liver, but 


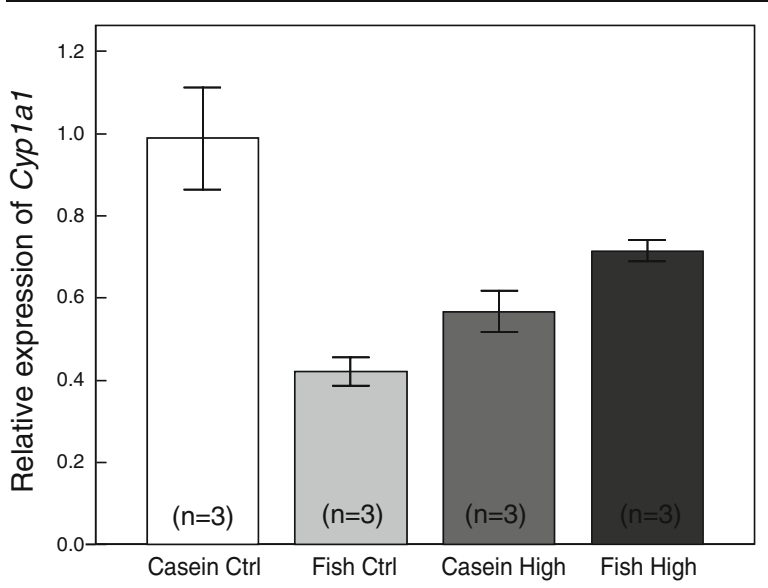

Fig. 4 Relative expression of Cyplal in liver. Relative expression levels in RT-qPCR for Cyplal in livers of maternally exposed offspring on PND18. Bars and error bars signify mean \pm SEM. Ctrl Control

there were no significant differences among groups (Kruskal-Wallis, exact test, $p>0.6$ for each gene).

\section{Discussion}

Tissue levels and exposure regime

The study investigated the neurotoxicity of BDE47 exposure to mice at the most vulnerable period of brain development, using an exposure pathway relevant to humans. Two experimental levels were tested and represented a realistic and an extreme scenario. However, it needs to be considered that the toxicokinetics of BDE47 in mice are different from humans, and direct extrapolation to human effects is thus not warranted. Mice are widely used as models in studies of neurotoxicity and in neurological research (Tilson 1991; Bignami et al. 1992; Eriksson 1996; Branchi et al. 2002; Darnerud 2003; Viberg 2004; Eriksson et al. 2006). However, mice have a much more rapid excretion of BDE47 than humans (Orn and Klasson-Wehler 1998; Staskal et al. 2005), and the risks to humans may therefore be underestimated using mice as a model organism.

Accumulation in pup brains (up to $\sim 80 \mathrm{ng} / \mathrm{g} \mathrm{ww}$ ) reflected maternal dietary intake. The results of the present study suggest that the current BDE47 exposure did not notably affect physical or neurobehavioural development in mice. Only one gene was found to be consistently regulated by both microarray and RT-qPCR in the casein high level group, and additionally two genes were found to be regulated by RT-qPCR. However, most genes were not affected by the gestational and lactational BDE47 exposure in either casein or fish groups. Hepatic metabolic enzymes and thyroid responsive genes in pups were similarly not induced by the high exposure to BDE47, although studies have indicated that a limited hepatic metabolism is present at the age of weaning in mice (Staskal et al. 2005).

The feed contaminant load was largely restricted to BDE47, and the concentrations of other contaminants were very low. Using a virtually clean control feed with negligible levels of other environmental contaminants was advantageous to delineate the results to effects of BDE47 alone and diminished the problem of additive, synergistic or antagonistic effects, which might have precluded the interpretation. This was achieved using fish samples raised on low contaminant diets. BDE47 is the most prevalent PBDE congener in human samples, comprising over 50\% of the PBDEs in breast milk (Meironyte et al. 1999; Noren and Meironyte 2000), and identification of effects of exposure to this congener is thus valuable. The exposure to metabolites of BDE47, which is achieved via lactational transfer, is highly realistic when attempting to mimic maternal exposure in breastfed infants.

Previous studies that have found PBDE-induced cognitive impairment and altered activity have often used a single oral dose of $1.4 \mu \mathrm{mol} / \mathrm{kg} \mathrm{BW}$ (Eriksson et al. 2001), which is higher than the average daily dose to dams used in this study and similar to the peak dose during lactation. Estimations based on previous publications (Darnerud and Risberg 2006) suggested that pups would receive a daily dose per kilogram BW that would be higher than the single oral dose previously administered on PND10. The analyses of brain tissue in this study showed that the concentrations of BDE47 in brains on PND18 were high and similar to those reported previously, where $1 \mathrm{mg} \mathrm{BDE} 47 / \mathrm{kg}$ BW had been given orally to mice pups on PND22 (Staskal et al. 2006). The oral dose given on PND22 (Staskal et al. 2006) was comparable to the dose shown to induce behavioural effects after neonate oral exposure to a single dose on PND10 in mice (Eriksson et al. 2001). This shows that the maternal exposure mode used for this study represents an efficient transfer of BDE47 to pups and that the 
accumulated dose received by the pups was comparable to the single oral dose used in studies that have previously shown behavioural effects after pup exposure (Eriksson et al. 2001, 2002, 2006; Viberg et al. 2003a,b, 2004; Suvorov et al. 2009). However, using maternal exposure to mimic human exposure complicates direct comparison to previous studies where behavioural effects have been demonstrated after direct oral dosing to pups. The present study may also suggest that a single, high bolus dose during brain growth may be more toxic than a continuous chronic exposure, even if comparable levels are present in the brains at the vulnerable time of BGS. However, an acute and high exposure is rarely experienced in humans, and exposure via the mother may better mimic chronic human exposure.

\section{Toxic effects of continuous BDE47 exposure}

The finding that the continuous maternal exposure to BDE47 during gestation and lactation has little effect on growth, weight gain or physical and early neurobehavioural development in the offspring supports previous findings (Gee and Moser 2008). The present study suggested a possible low-grade effect on early reflex development, but no effects of exposure could be detected on PND18, indicating that any early reflex impairment was transient. Previous studies have documented the validity and efficiency of the neurobehavioural tests used and have previously detected neurobehavioural differences in mouse pups exposed to seafood toxicants (Folven et al. 2009; Glover et al. 2009). It seems to be a recurring finding that PBDEs do not overtly affect physical development or reflex development and motor coordination (Branchi et al. 2002; Gee and Moser 2008; Suvorov et al. 2009). However, complex behaviour, such as habituation, learning and spontaneous activity, have consistently been affected by several PBDEs including BDE47 (Viberg et al. 2003a,b, 2004, 2006). This effect of PBDEs on the complex cognitive functions also gain support from recent human epidemiological studies (Herbstman et al. 2010). The lack of effects in spontaneous behaviour and reactivity in the elevated plus maze may be due to the immature behaviour of the pre-weanling pups, which made spontaneous testing difficult. In order to differentiate between groups, a certain range of behaviour must be displayed. The spontaneous and exploratory behav- iour of the pups in the elevated plus maze was different from adult-like behaviour in that they did not actively explore the arena (Cuomo et al. 1996). The pre-weanling pups showed similar limited behaviour as described by Glover et al. (2009) at PND15. Extending the time spent in the elevated plus maze was not feasible at this age. It was considered unlikely that such an extension would have altered pup behaviour to a great extent.

Concerning the age of testing, previous studies indicate that behavioural responses to perinatal PBDE exposure during development manifests in adulthood (Eriksson et al. 2001; Viberg et al. 2003b), and it is possible that an overt behavioural response had not developed at the time of testing. Such "silent neurotoxicity" has previously been reported for both drugs and toxicants (Reuhl 1991; review by Costa et al. 2004).

The toxicogenomic approach aimed at detecting the early changes that were believed to precede behavioural changes in adulthood and thus help delineate the mechanisms of BDE47 toxicity. Sensitive molecular methods indicated significant geneexpression regulation of three of the investigated genes (Glul, Rara and Igfbp2) at the investigated time point. Glul was the most highly regulated gene in this study (Table 2). Finding a total of three regulated genes among 37,000 genes on the microarray slide does not point to an immense impact of the current exposure on gene expression regulation. On the other hand, the finding of regulation of Glul is further supported by the glutamate signalling pathway in IPA being significantly associated with several other regulated genes from the present study.

Regulation of Glul may have consequences for the CNS. Upregulation of Glul could be interpreted as a compensation for a disturbance in glutamine synthesis or neurotransmission. Glul takes part in the removal of glutamate, which is one of the major neurotransmitters in the brain. Moreover, glutamate is among the excitatory amino acids (EAA) that have great potential for involvement in neurodegenerative disease (Olney 1990) and may be a mechanistic link to the development of attention deficit hyperactive disorder. Disruptions of the EAA balance during development, both in the form of too high or too low levels, may lead to neurological disorders (Olney 1990). Glutamate is also a ligand for the $N$-methyl-Daspartate (NMDA) receptor (Grin1, Table 2), which 
was regulated according to microarray analyses. NMDA also plays a large role in the mechanisms of excitotoxicity (Olney 1990). However, in the qPCR validation, the gene for the NMDA receptor was found not to be significantly regulated. Nevertheless, the effects of disruption and a time of vulnerability to EAAs postulated by Olney (1990) are highly interesting in light of the later behavioural changes observed by Eriksson (1997) and Viberg et al. (2003b). The present study thus lends some support to these previous studies, which may be of interest for future investigations.

The present study also supported the previously published up regulation of $I g f b 2$ in the brain after BDE47 exposure (Suvorov et al. 2011) but did not observe the same regulation of $I g f b 2$ in the liver.

The third regulated gene described in the current analysis, Rara, has previously been used as a biomarker for environmental pollutants (review by Novak et al. 2008) and was also indicated as a gene of interest by these groups after exposure of mice to BDE47 (data not published). Another gene, Prkce, was indicated as downregulated in microarrays for this and a previous study (Suvorov et al. 2011), but not validated by RT-qPCR in either study. Moreover, the enzyme protein kinase $\mathrm{C}$ has been found to be affected by PBDEs in previous in vitro studies (Kodavanti and Ward 2005). Although not validated in the present study, these findings suggest that the four mentioned genes may be of interest for future research concerning mechanisms for PBDE toxicity.

Most genes in the present study showed no significant regulation in RT-qPCR. This corresponded well to the original IPA filtering of microarray results, where no genes passed the filter as significantly regulated. The microarray analyses and RT-qPCR validations also indicated that changes were small when present. This indicates that BDE47 exposure does not induce cerebral gene-expression changes at this age and under the current mode of exposure.

Based on this study and previous publications, the gene expression in the brain seems remarkably stable and expression changes in response to non-biotic stimuli seem generally low. Previous studies have reported relatively low fold changes in cerebral geneexpression after exposure to mixtures of PCBs, methyl mercury and organochlorines (Padhi et al. 2008; Royland and Kodavanti 2008; Royland et al. 2008; Glover et al. 2009). The marginal regulation of gene expression in the present study may also reflect the relatively low concentrations of PBDEs found in brains compared to other tissues, such as the liver.

In support of the seemingly low toxicity in the present study, none of the examined genes for hepatic metabolic enzymes were regulated by exposure to BDE47, although xenobiotic metabolic capacity has been demonstrated at the age of weaning (Staskal et al. 2006). This suggests that the hepatic toxicity of BDE47 is limited or that commonly used markers of toxicity are not induced by BDE47. Similarly, the present study did not support the previously published regulation of $I g f b 2$ or $N f 1 B$ in the liver after BDE47 exposure (Suvorov et al. 2011). However, differences between studies may be caused by inter-species differences and the different modes of exposure used.

The result of the study does not exclude that possible effects of PBDE exposure may be measurable in pups by other methods or at different time points. For example, the age of sampling for microarray analysis is of importance, as previously demonstrated (Royland and Kodavanti 2008), and the present study may have missed the peak of gene-expression regulation. Compensatory mechanisms induced by the long-term exposure may also have reduced the responses, or the responses may be delayed, suggesting that time of sampling might be a key facet in determining changes in cerebral gene expression.

\section{Conclusion}

BDE47 accumulated in the brain of maternally exposed mice, reflecting the maternal intake. The accumulated levels of BDE47 in the brain did not exert measurable effects on physical development or reflexes in 18-dayold pups. Changes related to BDE47 exposure and diets were found by microarray and RT-qPCR analysis of global cerebral gene expression in mouse pups and may suggest effects in the area of neurodevelopment and cell-to-cell signalling via disturbance of the glutamate signalling system and genes involved in signal transduction, growth and maturation of the CNS. The effects that were observed by a toxicogenomic approach occurred in the high level group where dams were fed BDE47 in a casein-based diet. No significant effects were detected in the group where dams were fed high levels of BDE47 in a fish-based diet, which indicates a potential ameliorating effect of nutrients on PBDE- 
induced gene expression changes. The present study indicates that toxic effects of BDE47 on the brain and liver may not be manifested as detectable gene regulation, even after a continuous high exposure to the congener during a vulnerable phase of foetal and neonatal development. This does not exclude that changes may be present and detectable by methods that were not investigated in this study. Targeted investigation of pathways and gene products outlined in the present study may further elucidate the mechanisms of effect of PBDEs, which have lead to the previously observed behavioural changes in mice offspring after perinatal PBDE exposure.

Acknowledgements This study was funded by the EC 6th FRP Integrated project-program AQUAMAX (EU contract no. 016249-2), and the National Institute of Nutrition and Seafood Research (NIFES), Norway. The authors would like to express gratitude towards Dr. Anne-Vatland Krøvel, Eva Mykkeltvedt and Hui-Shan Tung, Aase Heltveit, Edel Erdal, Shalini Jayashankar and technical staff at NIFES. Additional thanks to Valentina Reffatto, Josef D. Rasinger, Dr. Matthew Arno and Dr. Estibaliz Aldecoa-Otalora Astarloa at KCL for scientific input and technical assistance.

Open Access This article is distributed under the terms of the Creative Commons Attribution Noncommercial License which permits any noncommercial use, distribution, and reproduction in any medium, provided the original author(s) and source are credited.

\section{References}

Alsharif NZ, Hassoun EA. Protective effects of vitamin A and vitamin E succinate against 2,3,7,8-tetrachlorodibenzo-pdioxin (TCDD)-induced body wasting, hepatomegaly, thymic atrophy, production of reactive oxygen species and DNA damage in $\mathrm{C} 57 \mathrm{BL} / 6 \mathrm{~J}$ mice. Basic Clin Pharmacol Toxicol. 2004;95:131-8.

Bajetto A, Bonavia R, Barbero S, Florio T, Schettini G. Chemokines and their receptors in the central nervous system. Front Neuroendocrinol. 2001;22:147-84.

Behnisch PA, Hosoe K, Sakai S. Brominated dioxin-like compounds: in vitro assessment in comparison to classical dioxin-like compounds and other polyaromatic compounds. Environ Int. 2003;29:861-77.

Benjamini Y, Hochberg Y. Controlling the false discovery rate-a practical and powerful approach to multiple testing. J Royal Stat Soc Ser B. 1995;57:289-300.

Berntssen MHG, Julshamn K, Lundebye AK. Chemical contaminants in aquafeeds and Atlantic salmon (Salmo salar) following the use of traditional- versus alternative feed ingredients. Chemosphere. 2010;78:637-46.

Bethune C, Julshamn K, Lundebye AK. A preliminary comparison of polybrominated diphenyl ether concentrations relative to lipid content and to levels of dioxins and dioxinlike polychlorinated biphenyls in Norwegian farmed Atlantic salmon (Salmo salar). Int J Food Sci Technol. 2005;40:143-8.

Bethune C, Seierstad SL, Seljeflot I, Johansen O, Arnesen H, Meltzer HM, et al. Dietary intake of differently fed salmon: a preliminary study on contaminants. Eur J Clin Investig. 2006;36:193-201.

Bignami G. Economical test methods for developmental neurobehavioral toxicity. Environ Health Perspect. 1996;104 Suppl 2:285-98.

Bignami G, Laviola G, Alleva E, Cagiano R, Lacomba C, Cuomo V. Developmental aspects of neurobehavioural toxicity. Toxicol Lett. 1992;64-65(Spec. No.):231-237.

Bonham MP, Duffy EM, Robson PJ, Wallace JM, Myers GJ, Davidson PW, et al. Contribution of fish to intakes of micronutrients important for fetal development: a dietary survey of pregnant women in the Republic of Seychelles. Public Health Nutr. 2009;12:1312-20.

Bourre JM. Effects of nutrients (in food) on the structure and function of the nervous system: update on dietary requirements for brain. Part 1: micronutrients. J Nutr Health Aging. 2006; 10:377-85.

Branchi I, Alleva E, Costa LG. Effects of perinatal exposure to a polybrominated diphenyl ether (PBDE 99) on mouse neurobehavioural development. Neurotoxicology. 2002;23:375-84.

Bustin SA, Benes V, Garson JA, Hellemans J, Huggett J, Kubista M, et al. The MIQE guidelines: minimum information for publication of quantitative real-time PCR experiments. Clin Chem. 2009;55:611-22.

Carroll T. Transcriptomic analysis of the neurotoxicity of relevant persistent organic pollutants in a salmon-based diet. Ph.D. thesis, Kings College London, London, UK; 2010.

Chambery D, de Galle B, Babajko S. Retinoic acid stimulates IGF binding protein (IGFBP)-6 and depresses IGFBP-2 and IGFBP-4 in SK-N-SH human neuroblastoma cells. J Endocrinol. 1998;159:227-32.

Chen G, Konstantinov AD, Chittim BG, Joyce EM, Bols NC, Bunce NJ. Synthesis of polybrominated diphenyl ethers and their capacity to induce CYP1A by the Ah receptor mediated pathway. Environ Sci Technol. 2001;35:374956.

Costa LG, Aschner M, Vitalone A, Syversen T, Soldin OP. Developmental neuropathology of environmental agents. Annu Rev Pharmacol Toxicol. 2004;44:87-110.

Cuomo V, De Salvia MA, Petruzzi S, Alleva E. Appropriate end points for the characterization of behavioral changes in developmental toxicology. Environ Health Perspect. 1996;104 Suppl 2:307-15.

Darnerud PO. Toxic effects of brominated flame retardants in man and in wildlife. Environ Int. 2003;29:841-53.

Darnerud PO, Risberg S. Tissue localisation of tetra- and pentabromodiphenyl ether congeners (BDE-47, -85 and -99) in perinatal and adult C57BL mice. Chemosphere. 2006;62:485-93.

Dolinoy DC, Huang D, Jirtle RL. Maternal nutrient supplementation counteracts bisphenol A-induced DNA hypomethylation in early development. Proc Natl Acad Sci USA. 2007;104:13056-61. 
EFSA. Opinion of the scientific panel on contaminants in the food chain on a request from the European Parliament related to the safety assessment of wild and farmed fish. EFSA J 236. http://www.efsa.europa.eu/cs/BlobServer/ Scientific_Opinion/contam_opinion_ej236_swaff_v2_en1. pdf?ssbinary=true (2005).

Eriksson P. Developmental neurotoxicology in the neonateeffects of pesticides and polychlorinated organic substances. Arch Toxicol Suppl. 1996;18:81-8.

Eriksson P. Developmental neurotoxicity of environmental agents in the neonate. Neurotoxicology. 1997;18:71926.

Eriksson P, Jakobsson E, Fredriksson A. Brominated flame retardants: a novel class of developmental neurotoxicants in our environment? Environ Health Perspect. 2001;109:903-8.

Eriksson P, Viberg H, Jakobsson E, Orn U, Fredriksson A. A brominated flame retardant, 2,2',4,4',5-pentabromodiphenyl ether: uptake, retention, and induction of neurobehavioral alterations in mice during a critical phase of neonatal brain development. Toxicol Sci. 2002;67:98-103.

Eriksson P, Fischer C, Fredriksson A. Polybrominated diphenyl ethers (PBDEs), a group of brominated flame retardants, can interact with PCB in enhancing developmental neurobehavioral defects. Toxicol Sci. 2006;94(2):302309.

Folven KI, Glover C, Malde MK, Lundebye AK. Does selenium modify neurobehavioural impacts of developmental methylmercury exposure in mice? Environ Toxicol Pharmacol. 2009;28:111-9.

Fox WM. Reflex-ontogeny and behavioural development of the mouse. Anim Behav. 1965;13:234-41.

Furst P. Dioxins, polychlorinated biphenyls and other organohalogen compounds in human milk. Levels, correlations, trends and exposure through breastfeeding. Mol Nutr Food Res. 2006;50:922-33.

Gee JR, Moser VC. Acute postnatal exposure to brominated diphenylether 47 delays neuromotor ontogeny and alters motor activity in mice. Neurotoxicol Teratol. 2008;30:7987.

Gee J, Moser V, McDaniel K, Herr D. Acute developmental exposure to polybrominated diphenyl ether 47 (PBDE 47) alters dopamine concentration within the brain of male mice. Neurotoxicol Teratol. 2008;30:258.

Geurts JM, Schoenmakers EF, Roijer E, Astrom AK, Stenman $\mathrm{G}$, van de Ven WJ. Identification of NFIB as recurrent translocation partner gene of HMGIC in pleomorphic adenomas. Oncogene. 1998;16:865-72.

Glover CN, Zheng D, Jayashankar S, Sales GD, Hogstrand C, Lundebye AK. Methylmercury speciation influences brain gene expression and behavior in gestationally-exposed mice pups. Toxicol Sci. 2009;110:389-400.

Guvenius DM, Aronsson A, Ekman-Ordeberg G, Bergman A, Noren K. Human prenatal and postnatal exposure to polybrominated diphenyl ethers, polychlorinated biphenyls, polychlorobiphenylols, and pentachlorophenol. Environ Health Perspect. 2003;111:1235-41.

Haave M, Bernhard A, Folven KI, Brattelid T, Lundebye A-K. Fish consumption reduces transfer of persistent organic pollutants from dam to murine offspring. Chemosphere. 2011;84:348-354.
Hamre K, Kolas K, Sandnes K. Protection of fish feed, made directly from marine raw materials, with natural antioxidants. Food Chem. 2010;119:270-8.

He P, He W, Wang A, Xia T, Xu B, Zhang M, et al. PBDE-47induced oxidative stress, DNA damage and apoptosis in primary cultured rat hippocampal neurons. Neurotoxicology. 2008;29:124-9.

Herbstman JB, Sjodin A, Kurzon M, Lederman SA, Jones RS, Rauh V, et al. Prenatal exposure to PBDEs and neurodevelopment. Environ Health Perspect. 2010;118:712-9.

Holson RR, Pearce B. Principles and pitfalls in the analysis of prenatal treatment effects in multiparous species. Neurotoxicol Teratol. 1992;14:221-8.

Horvli O, Lie $\varnothing$. Determination of vitamin D3 in fish meals by HPLC. Fiskeridirektoratets Skrifter, Serie Ernæring. 1994;6:163-175.

Hu W, Sorrentino C, Denison MS, Kolaja K, Fielden MR. Induction of cyplal is a nonspecific biomarker of aryl hydrocarbon receptor activation: results of large scale screening of pharmaceuticals and toxicants in vivo and in vitro. Mol Pharmacol. 2007;71:1475-86.

Julshamn K, Maage A, Norli HS, Grobecker KH, Jorhem L, Fecher P. Determination of arsenic, cadmium, mercury, and lead by inductively coupled plasma/mass spectrometry in foods after pressure digestion: NMKL1 interlaboratory study. J AOAC Int. 2007;90:844-56.

Knutsen HK, Kvalem HE, Thomsen C, Froshaug M, Haugen $M$, Becher $G$, et al. Dietary exposure to brominated flame retardants correlates with male blood levels in a selected group of Norwegians with a wide range of seafood consumption. Mol Nutr Food Res. 2008;52:217-27.

Kodavanti PR. Neurotoxicity of persistent organic pollutants: possible mode(s) of action and further considerations. Dose Response. 2005;3:273-305.

Kodavanti PR, Derr-Yellin EC. Differential effects of polybrominated diphenyl ethers and polychlorinated biphenyls on $[3 \mathrm{H}]$ arachidonic acid release in rat cerebellar granule neurons. Toxicol Sci. 2002;68:451-7.

Kodavanti PR, Ward TR. Differential effects of commercial polybrominated diphenyl ether and polychlorinated biphenyl mixtures on intracellular signaling in rat brain in vitro. Toxicol Sci. 2005;85:952-62.

Lie O, Lambertsen G. Fatty acid composition of glycerophospholipids in seven tissues of cod (Gadus morhua), determined by combined high-performance liquid chromatography and gas chromatography. J Chromatogr. 1991;565:119-29.

Meironyte D, Noren K, Bergman A. Analysis of polybrominated diphenyl ethers in Swedish human milk. A timerelated trend study, 1972-1997. J Toxicol Environ Health A. 1999;58:329-41.

Moren M, Naess T, Hamre K. Conversion of beta-carotene, canthaxanthin and astaxanthin to vitamin $\mathrm{A}$ in Atlantic halibut (Hippoglossus hippoglossus L.) juveniles. Fish Physiol. Biochem. 2002;27:71-80.

Noren K, Meironyte D. Certain organochlorine and organobromine contaminants in Swedish human milk in perspective of past 20-30 years. Chemosphere. 2000;40:1111-23.

Novak J, Benisek M, Hilscherova K. Disruption of retinoid transport, metabolism and signaling by environmental pollutants. Environ Int. 2008;34:898-913. 
NS9402. Atlantic salmon. Measurement of colour and fat. Norges Standardiseringsforbund, Oslo; 1994.

Olney JW. Excitotoxic amino acids and neuropsychiatric disorders. Annu Rev Pharmacol Toxicol. 1990;30:47-71.

Olsvik PA, Lie KK, Goksoyr A, Midtun T, Frantzen S, Maage A. Are Atlantic cod in Store Lungegardsvann, a seawater recipient in Bergen, affected by environmental contaminants? A qRT-PCR survey. J Toxicol Environ Health A. 2009;72:140-54.

Orn U, Klasson-Wehler E. Metabolism of 2,2',4,4'-tetrabromodiphenyl ether in rat and mouse. Xenobiotica. 1998;28:199-211.

Pacyniak EK, Cheng X, Cunningham ML, Crofton K, Klaassen CD, Guo GL. The flame retardants, polybrominated diphenyl ethers, are pregnane $\mathrm{X}$ receptor activators. Toxicol Sci. 2007;97:94-102.

Padhi BK, Pelletier G, Williams A, Berndt-Weis L, Yauk C, Bowers WJ, et al. Gene expression profiling in rat cerebellum following in utero and lactational exposure to mixtures of methylmercury, polychlorinated biphenyls and organochlorine pesticides. Toxicol Lett. 2008;176:93-103.

Peraza MA, Ayala-Fierro F, Barber DS, Casarez E, Rael LT. Effects of micronutrients on metal toxicity. Environ Health Perspect. 1998;106 Suppl 1:203-16.

Peters AK, Nijmeijer S, Gradin K, Backlund M, Bergman A, Poellinger $\mathrm{L}$, et al. Interactions of polybrominated diphenyl ethers with the aryl hydrocarbon receptor pathway. Toxicol Sci. 2006;92:133-42.

Piegorsch WW, Haseman JK. Statistical methods for analyzing developmental toxicity data. Teratog Carcinog Mutagen. 1991;11:115-33.

Pinheiro JC, Bates DM. Mixed-effects models in S and SPLUS. New York: Springer; 2000.

R Development Core Team R. A language and environment for statistical computing. R Foundation for Statistical Computing, Vienna; 2009.

Ransohoff RM, Liu L, Cardona AE. Chemokines and chemokine receptors: multipurpose players in neuroinflammation. Int Rev Neurobiol. 2007;82: 187-204.

Reistad T, Fonnum F, Mariussen E. Neurotoxicity of the pentabrominated diphenyl ether mixture, DE-71, and hexabromocyclododecane (HBCD) in rat cerebellar granule cells in vitro. Arch Toxicol. 2006;80:785-796.

Reuhl KR. Delayed expression of neurotoxicity: the problem of silent damage. Neurotoxicology. 1991;12:341-6.

Ritchie ME, Diyagama D, Neilson J, van Laar R, Dobrovic A, Holloway A, et al. Empirical array quality weights in the analysis of microarray data. BMC Bioinform. 2006;7:261.

Royland JE, Kodavanti PR. Gene expression profiles following exposure to a developmental neurotoxicant, Aroclor 1254: pathway analysis for possible mode(s) of action. Toxicol Appl Pharmacol. 2008;231:179-96.

Royland JE, Wu J, Zawia NH, Kodavanti PR. Gene expression profiles in the cerebellum and hippocampus following exposure to a neurotoxicant, Aroclor 1254: developmental effects. Toxicol Appl Pharmacol. 2008;231:165-78.

Sanders JM, Burka LT, Smith CS, Black W, James R, Cunningham ML. Differential expression of CYP1A, 2B, and $3 \mathrm{~A}$ genes in the $\mathrm{F} 344$ rat following exposure to a polybrominated diphenyl ether mixture or individual components. Toxicol Sci. 2005;88:127-33.
Sanders JM, Chen LJ, Lebetkin EH, Burka LT. Metabolism and disposition of 2,2',4,4'- tetrabromodiphenyl ether following administration of single or multiple doses to rats and mice. Xenobiotica. 2006;36:103-17.

Smyth GK. Linear models and empirical bayes methods for assessing differential expression in microarray experiments. Stat Appl Genet Mol Biol. 2004;3:article 3.

Smyth GK. Limma: linear models for microarray data. In: Gentleman VCR, Dudoit S, Irizarry R, Huber W (eds) Bioinformatics and computational biology solutions using $\mathrm{R}$ and bioconductor. Springer, New York; 2005. p. 397-420.

Staskal DF, Diliberto JJ, DeVito MJ, Birnbaum LS. Toxicokinetics of BDE 47 in female mice: effect of dose, route of exposure, and time. Toxicol Sci. 2005;83:215-23.

Staskal DF, Diliberto JJ, Birnbaum LS. Disposition of BDE 47 in developing mice. Toxicol Sci. 2006;90:309-16.

Strachan T, Read AP. Human molecular genetics. 2nd ed. New York: Bios Scientific; 1999.

Suvorov A, Girard S, Lachapelle S, Abdelouahab N, Sebire G, Takser L. Perinatal exposure to low-dose BDE-47, an emergent environmental contaminant, causes hyperactivity in rat offspring. Neonatology. 2009;95:203-9.

Suvorov A, Bissonnette C, Takser L, Langlois MF. Does 2,2',4,4'-tetrabromodiphenyl ether interact directly with thyroid receptor? J Appl Toxicol. 2011;31:179-184. doi:10.1002/jat.1580.

Thomsen C, Knutsen HK, Liane VH, Froshaug M, Kvalem HE, Haugen $\mathrm{M}$, et al. Consumption of fish from a contaminated lake strongly affects the concentrations of polybrominated diphenyl ethers and hexabromocyclododecane in serum. Mol Nutr Food Res. 2008;52:228-37.

Tilson HA. Study design considerations in developmental neurotoxicology. Neurotoxicol Teratol. 1991;14:199-203.

Torstensen BE, Espe M, Sanden M, Stubhaug I, Waagbø R, Hemre GI, et al. Novel production of Atlantic salmon (Salmo salar) protein based on combined replacement of fish meal and fish oil with plant meal and vegetable oil blends. Aquaculture. 2008;285:193-200.

Umegaki K, Ikegami S. Feeding fish oil to rats accelerates the metabolism of hexachlorobenzene. J Nutr Sci Vitaminol (Tokyo). 1998;44:301-11.

Umegaki K, Ikegami S, Ichikawa T. Fish oil enhances pentachlorobenzene metabolism and reduces its accumulation in rats. J Nutr. 1995;125:147-53.

Verheyde J, de Saint-Georges L, Leyns L, Benotmane MA. The role of Trp53 in the transcriptional response to ionizing radiation in the developing brain. DNA Res. 2006;13:65-75.

Viberg H, Fredriksson A, Eriksson P. Neonatal exposure to polybrominated diphenyl ether (PBDE 153) disrupts spontaneous behaviour, impairs learning and memory, and decreases hippocampal cholinergic receptors in adult mice. Toxicol Appl Pharmacol. 2003a;192:95-106.

Viberg H, Fredriksson A, Jakobsson E, Orn U, Eriksson P. Neurobehavioral derangements in adult mice receiving decabrominated diphenyl ether (PBDE 209) during a defined period of neonatal brain development. Toxicol Sci. 2003b;76:112-20.

Viberg H. Neonatal developmental neurotoxicity of brominated flame retardants, the polybrominated diphenyl ethers (PBDEs). Ph.D. thesis. Uppsala University, Uppsala, Sweden; 2004. 
Viberg H, Fredriksson A, Eriksson P. Investigations of strain and/or gender differences in developmental neurotoxic effects of polybrominated diphenyl ethers in mice. Toxicol Sci. 2004;81:344-53.

Viberg H, Johansson N, Fredriksson A, Eriksson J, Marsh G, Eriksson P. Neonatal exposure to higher brominated diphenyl ethers, hepta-, octa-, or nonabromodiphenyl ether, impairs spontaneous behavior and learning and memory functions of adult mice. Toxicol Sci. 2006;92:211-8.

Viberg H, Mundy W, Eriksson P. Neonatal exposure to decabrominated diphenyl ether (PBDE 209) results in changes in BDNF, CaMKII and GAP-43, biochemical substrates of neuronal survival, growth, and synaptogenesis. Neurotoxicology. 2008;29:152-9.

WHO/FAO. Joint WHO/FAO expert consultation on diet, nutrition and the prevention of chronic diseases. WHO technical report series, no. 916. http:/www.fao.org/ docrep/005/ac911e/ac911e00.htm (2002). Accessed March 2010.

Zuur AF, Leno EN, Walker N, Saveliev AA, Smith GM. Mixed effects models and extensions in ecology with R. Springer, Berlin; 2009. p. 574. 